\title{
PENERAPAN MODEL PEMBELAJARAN KOOPERATIF TIPE THINK PAIR SHARE (TPS) UNTUK MENINGKATKAN KEMAMPUAN PEMECAHAN MASALAH MATEMATIKA SISWA
}

\author{
Asep Sujana ${ }^{1}$ dan Maskhopipah \\ 1asep.sujana@unmabanten.ac.id
}

\begin{abstract}
ABSTRAK
Salah satu problematika dalam pembelajaran matematika adalah masih rendahnya kemampuan pemecahan masalah matematika. Hal ini ditunjukan dengan rendahnya kamampuan siswa dalam menyelesaikan soal-soal yang diberikan, terlebih persoalan yang berkaitan dengan dunia nyata.Penelitian ini bertujuan untuk mengetahui pengaruh penggunaan model pembelajaran Kooperatif Tipe Think Pair Share (TPS) terhadap Peningkatan Kemampuan Pemecahan Masalah Matematika Siswa pada pokok bahasan aljabar Kelas VIII SMP. Penelitian dilakukan menggunakan metode kuasi eksperimen. Pengambilan sampel dilakukan dengan teknik purposive sampling. Berdasarkan hasil penelitian dan analisis data, diperoleh $t_{\text {hitung }}=$ 6,7892 dan $t_{\text {tabel }} 1,6723$ pada taraf signifikansi $5 \%$ dan $\mathrm{dk}=60$. Karena $t_{\text {hitung }}>$ $t_{\text {tabel }}(6,7892>1,6723)$ maka $\mathrm{H}_{0}$ ditolak dan $\mathrm{H}_{1}$ diterima. Hal tersebut menunjukan bahwa terdapat pengaruh model pembelajaran Think Pair Share (TPS) terhadap peningkatan kemampuan pemecahan masalah matematika siswa kelas VIII SMP. Jadi kemampuan pemecahan masalah siswa yang menggunakan model pembelajaran Think Pair Share lebih baik dibandingkan siswa yang menggunakan model pembelajaran ceramah.
\end{abstract}

Kata Kunci: Pembelajaran Kooperatif, Think Pair Share (TPS), Kemampuan Pemecahan Masalah,

\begin{abstract}
One of the problem in matematics learning is the ability of matematics problem solving is still low. It is shown from the students' low ability in solving the questions of mathematisc exercises, especially in the relation to real life problem. The research aims to find out the influence of the use of Cooperatiflearning model, Think Pair Share (TPS) towards the increase of students' problem solving ability in the algebra lesson for Junior high school students grade $9^{\text {th }}$. The research was conducted by using quasi eksperimental method. The purposive sampling technique is used to get the sample. Based on the result of the research and data analysis, it gets $t_{\text {hitung }}=6,7892$ and $t_{\text {tabel }} 1,6723$ on significant level $5 \%$ and $\mathrm{dc}=60$. Because of $t_{\text {hitung }}>t_{\text {tabel }}(6,7892>1,6723)$, so $\mathrm{H}_{0}$ is rejected and $\mathrm{H}_{1}$ is accepted. It shows that there is the influence of Think Pair Share (TPS) towards the increase of students' problem solving for Junior high school students grade $9^{\text {th }}$. Therefore, the ability of students' problem solving that use Think Pair Share (TPS) are better than the students who use lecturing learning model.
\end{abstract}

Keyword: Cooperatif learning model, Think Pair Share (TPS), problem solving 


\section{A. PENDAhULUAN}

Berbagai permasalahan yang sering dihadapi dalam pembelajaran biasanya berkaitan dengan mata pelajaran ataupun yang berhubungan dengan kehidupan sosial. Dalam pembelajaran matematika dapat menggali kemampuan pemechan masalah. Untuk memperoleh pemecahan maslah tersebut dapat dilakukan dengan diskusi, tanya jawab antara guru dan siswa, penemuan dan inkuiri.

Menurut NCTM atau National Council of Teachers Mathematics (Maryanti, 2012:5) terdapat lima kompetensi dalam pembelajaran matematika, yaitu: pemecahan masalah matematis (mathematical problem solving), komunikasi matematis (mathematical communication), penalaran matematis (mathematical reasoning), koneksi matematis (mathematical connection), dan representasi matematis (mathematical representation). Kelima kompetensi tersebut sangat diperlukan untuk kehidupan mahasiswa sehingga menjadi warga negara yang kreatif dan bermanfaat sesuai dengan tujuan pendidikan nasional dalam Permendiknas No. 22 tahun 2006 yaitu untuk mengembangkan potensi peserta didik agar menjadi manusia yang beriman dan bertakwa kepada Tuhan Yang Maha Esa, berakhlak mulia, sehat, berilmu, cakap, kreatif, mandiri, dan menjadi warga negara yang demokratis serta bertanggung jawab.

Pada kenyataannya menunjukan banyaknya keluhan dari siswa tentang pelajaran matematika yang sulit, tidak menarik, membosankan serta sulit untuk dikomunikasikan. Keluhan ini secara langsung maupun tidak langsung akan sangat berpengaruh terhadap kemampuan matematika siswa pada setiap jenjang pendidikan, diantaranya adalah kemampuan pemecahan masalah matematika.

Berdasarkan hasil observasi di sekolah SMPN SATAP 5 Banjarsari, diperoleh data bahwa $60 \%$ dari siswa kelas VIII belum mencapai Kriteria Ketuntasan Minimal (KKM). Selain itu diperoleh fakta bahwa pemecahan masalah matematika siswa kelas VIII dalam menyelesaikan soal-soal pada materi faktorisasi suku aljabar cenderung rendah. Siswa masih banyak mengalami kendala dan masih mengalami kesulitan dalam memecahkan masalah, mereka belum dapat mengidentifikasi masalah dengan baik dan merumuskan masalahnya, terutama dalam merumuskan masalah, menyelesaikan masalah, sampai dengan menemukan solusi atau menuliskan kesimpulan dari jawaban yang dituliskan. 
Rendahnya kemampuan pemecahan masalah matematika siswa akan berdampak pada rendahnya prestasi siswa di sekolah. Kemampuan pemecahan masalah dapat digali melalui proses pembelajaran yang mendorong partisipasi siswa dalam komunikasi antara guru dengan siswa dan antara siswa dengan siswa. Dengan demikian, salah satu upaya untuk meningkatkan kemampuan pemecahan masalah matematika adalah dengan menggunakan model pembelajaran yang lebih menekankan pada keaktifan siswa.

Menurut Fogarty dan Robin (1996), model Think Pair Share adalah sebuah model yang mencakup tiga proses yaitu Think (berfikir secara mandiri mengenai pertanyaan atau masalah yang diajukan), Pair (berpasangan dengan teman yang sudah ditentukan oleh guru, sehingga dapat saling bertukar pikiran), dan Share (berbagi hasil pemikiran). Think Pair Share memiliki prosedur yang secara eksplisit memberi siswa waktu untuk berfikir, menjawab, saling membantu satu sama lain. Dengan demikian diharapkan siswa mampu bekerja sama, saling membutuhkan, dan saling bergantung pada kelompok kecil secara kooperatif.

Hasil penelitian Bubin (2012) menunjukkan bahwa pembelajaran dengan menggunakan model kooperatif tipeThink Pair Share dapat meningkatkan kemampuan pemecahan masalah matematika siswa. Adapun tujuan dari penelitian ini adalah untuk mengetahui pengaruh Model Pembelajaran kooperatif tipe Think Pair Share terhadap peningkatan kemampuan pemecahan masalah matematika pada materi faktorisasi suku aljabar kelas VIII.

\section{B. METODE PENELITIAN}

Penelitian ini termasuk jenis penelitian kuantitatif. Jenis penelitian yang akan dilakukan adalah penelitian kuasi eksperimen atau eksperimen semu karena peneliti tidak melakukan pengontrolan penuh terhadap variabel eksperimen. Untuk mendukung penelitian ini, maka diambil dua kelas secara acak. Kelas yang pertama merupakan kelas eksperimen yang diberi pembelajaran dengan model Think Pair Share, sedangkan kelas kedua merupakan kelas kontrol yang tidak diberi perlakuan atau dengan menggunakan metode ceramah. 
Adapun desain penelitian disajikan pada tabel 1.

Tabel 1.

Desain Penelitian Randomized Control Group Pretest-Postest

\begin{tabular}{lccc}
\hline Kelompok & Pretest & Treatment & Postest \\
\hline Eksperimen & $\mathrm{O}_{1}$ & $\mathrm{X}$ & $\mathrm{O}_{2}$ \\
Kontrol & $\mathrm{O}_{1}$ & - & $\mathrm{O}_{2}$ \\
\hline
\end{tabular}

Sumber : Ruseffendi ( 2005)

Keterangan:

$\mathrm{O}_{1}$ : Tes hasil belajar yang diberikan sebelum proses pembelajaran dimulai, diberikan kepada kelompok eksperimen dan kelompok kontrol.

$\mathrm{X}$ : Perlakuan pembelajaran dengan TPS

$\mathrm{O}_{2}$ : Pretest dan posttest berupa tes kemampuan pemecahan masalah matematika

\section{Teknik Pengumpulan Data}

Menurut Sugiyono (2013 : 308) Teknik pengumpulan data merupakan langkah yang paling utama dalam penelitian, karena tujuan utama dari penelitian adalah mendapatkan data. Tanpa mengetahui teknik pengumpulan data, maka peneliti tidak akan mendapatkan data yang memenuhi standar yang ditetapkan. Dalam penelitian teknik pengumpulan data yang digunakan dengan tes, instrumen yang berupa tes digunakan untuk mengetahui ada dan tidaknya perbedaan antara kelas kontrol dan eksperimen setelah diadakan perlakuan yang berbeda.

\section{Instrumen Penelitian}

Arikunto (2006: 160) instrumen penelitian adalah alat yang digunakan oleh peneliti dalam mengumpulkan data agar pekerjaan lebih mudah dan hasilnya lebih baik. Alat yang digunakan oleh peneliti sebagai alat pengumpulan data adalah tes dan lembar observasi.

Soal tes digunakan untuk mengukur kemampuan siswa dan diberikan kepada setiap siswa setelah siswa melakukan proses belajar. Soal tes yang akan digunakan adalah soal tes esay sebanyak 5 soal. Sementara bservasi digunakan untuk mengetahui kemampuan siswa tentang permasalahan dalam proses pembelajaran, model pembelajaran yang biasa digunakan serta kemampuan pemecahan masalah matematika. 


\section{HASIL PENELITIAN}

\section{Analisis Data Posttest}

Penelitian ini diakhiri dengan pemberian soal posstest yang ditujukan untuk mengukur kemampuan akhir pemecahan masalah matematika siswa. Soal posstest yang diberikan berupa soal uraian yang terdiri dari 5 butir soal yang sudah dilakukan ujicoba. Pemberian soal posstest berguna sebagai informasi akhir keadaan kelas, baik kelas kontrol maupun kelas eksperimen.

\section{a. Kelas Eksperimen}

Data posstes yang diperoleh dari 30 siswa pada kelas VIII A sebagai kelas eksperimen menghasilkan nilai terendah 45 dan tertinggi 85, nilai rata-rata 68,83, modus 63,17, median 67,25,serta simpangan baku 116,70. Distribusi frekuensi dapat dilihat pada tabel dibawah ini:

Tabel 1.

Distribusi Frekuensi Posstest Kelas Eksperimen

\begin{tabular}{crrrrrrr}
\hline Interval & $\boldsymbol{f}_{\boldsymbol{i}}$ & $\boldsymbol{x}_{\boldsymbol{i}}$ & \multicolumn{1}{c}{$\boldsymbol{x}_{\boldsymbol{i}}{ }^{2}$} & $\boldsymbol{f}_{\boldsymbol{i}}\left(\boldsymbol{x}_{\boldsymbol{i}}\right)$ & $\boldsymbol{f}_{\boldsymbol{i}}\left(\boldsymbol{x}_{\boldsymbol{i}}{ }^{2}\right)$ & Frekuensi Kumulatif & Frekuensi Relatif \\
\hline $45-51$ & 3 & 48 & 2304 & 144 & 6912 & 3 & $10 \%$ \\
$52-58$ & 2 & 55 & 3025 & 110 & 6050 & 5 & $7 \%$ \\
$59-65$ & 8 & 64 & 4096 & 512 & 32768 & 13 & $27 \%$ \\
$66-72$ & 5 & 69 & 4761 & 345 & 23805 & 24 & $17 \%$ \\
$73-79$ & 6 & 76 & 5776 & 456 & 34656 & 30 & $20 \%$ \\
$80-86$ & 6 & 83 & 6889 & 498 & 41334 & & $20 \%$ \\
& 30 & 395 & 26851 & 2065 & 145525 & $100 \%$ \\
\hline
\end{tabular}

Adapun sebaran data di atas dapat dilihat dalam diagram di bawah ini:

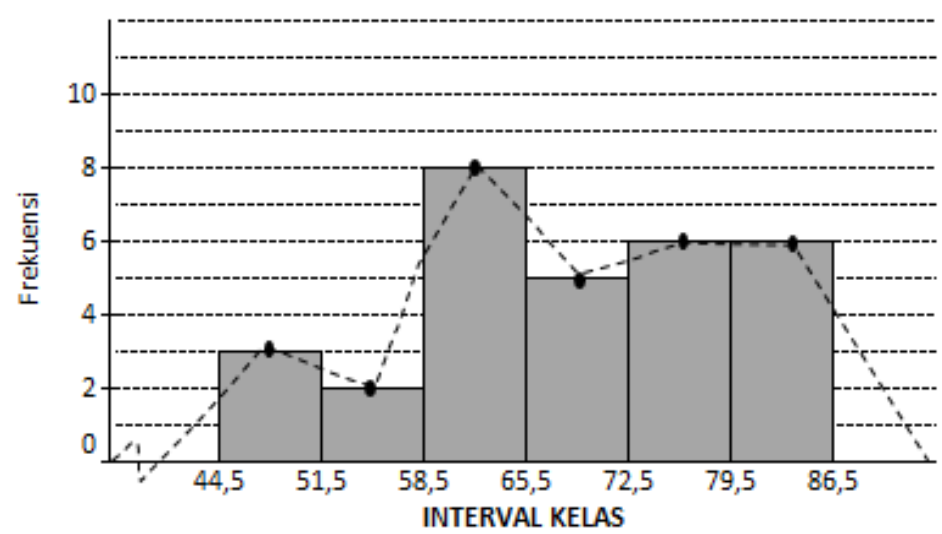

Diagram 1.

Histogram dan Poligon NilaiPosstest Kelas Eksperimen 


\section{b. Kelas Kontrol}

Data yang diperoleh dari 30 siswa pada kelas VIII Bsebagai kelas kontrol menghasilkan nilai terendah 35 dan tertinggi 75, skor rata-rata 54,33, modus 52,7, median53,59, serta simpangan baku 70,85.

Distribusi frekuensi data kemampuan pemecahan masalah matematika siswa yang mendapatkan model pembelajaran konvensionaldapat dilihat pada tabel dibawah:

Tabel 2.

Distribusi Frekuensi Posstest Kelas Kontrol

\begin{tabular}{crrrrrrr}
\hline Interval & \multicolumn{1}{c}{$\boldsymbol{f}_{\boldsymbol{i}}$} & $\boldsymbol{x}_{\boldsymbol{i}}$ & $\boldsymbol{x}_{\boldsymbol{i}}{ }^{2}$ & $\boldsymbol{f}_{\boldsymbol{i}}\left(\boldsymbol{x}_{\boldsymbol{i}}\right)$ & $\boldsymbol{f}_{\boldsymbol{i}}\left(\boldsymbol{x}_{\boldsymbol{i}}\right)^{\mathbf{2}}$ & $\begin{array}{c}\text { Frekuensi } \\
\text { Kumulatif }\end{array}$ & $\begin{array}{c}\text { Frekuensi } \\
\text { Relatif }\end{array}$ \\
\hline $35-41$ & 2 & 38 & 1444 & 76 & 2888 & 2 & $7 \%$ \\
$42-48$ & 5 & 45 & 2025 & 225 & 10125 & 7 & $17 \%$ \\
$49-55$ & 11 & 52 & 2704 & 572 & 29744 & 18 & $37 \%$ \\
$56-62$ & 7 & 59 & 3481 & 413 & 24367 & 25 & $23 \%$ \\
$63-69$ & 3 & 66 & 4356 & 198 & 13068 & 28 & $10 \%$ \\
$70-76$ & 2 & 73 & 5329 & 146 & 10658 & 30 & $7 \%$ \\
$\sum$ & 30 & 333 & 19339 & 1630 & 90850 & & $100 \%$ \\
\hline
\end{tabular}

Adapun Persebaran data diatas dapat dilihat dalam diagram dibawah ini:

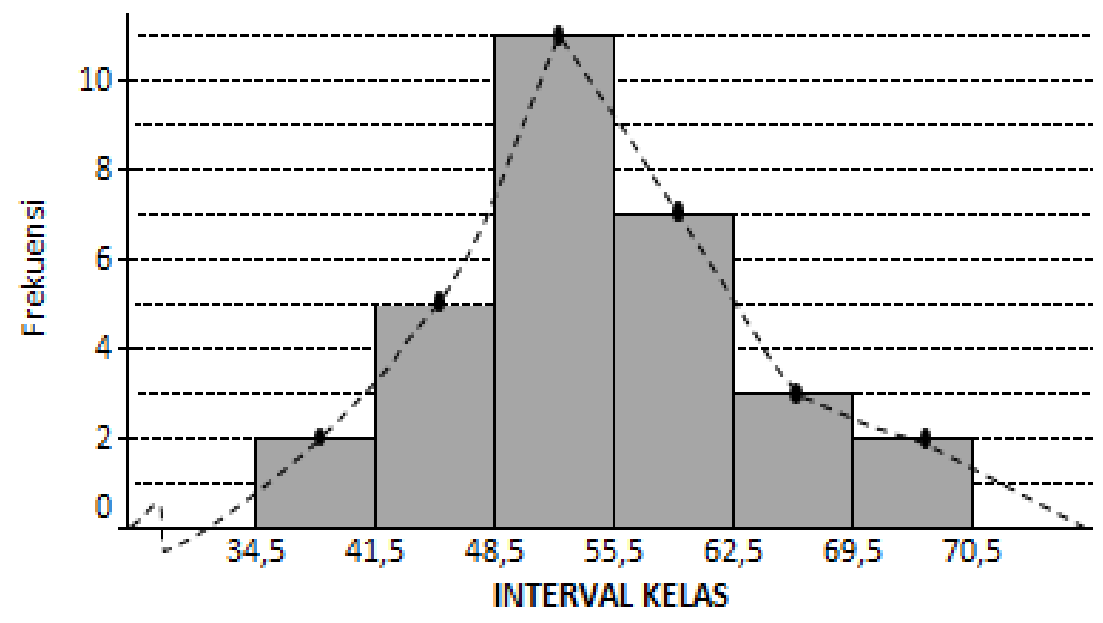

Diagram 2.

Histogram dan Poligon NilaiPosstest Kelas Kontrol

\section{Uji Hipotesis Data Pretest}

Uji hipotesis pada data pretestdigunakan untuk mengetahui apakah terdapat perbedaan kemampuan awal siswa kelas eksperimen dengan kelas kontrol.

Dengan hipotesis sebagai berikut: 
$\mathrm{H}_{0}$ : Tidak terdapat perbedaan kemampuan awal siswa kelas eksperimen dengan kelas kontrol.

$\mathrm{H}_{1}$ : Terdapat perbedaan kemampuan awal siswa kelas eksperimen dengan kelas kontrol.

Karena data pretest kelas kontrol dan kelas eksperimen berdistribusi normal dan varians kedua kelas homogen, maka uji hipotesis yang digunakan adalah uji-t, ini bertujuan untuk mengetahui apakah terdapat perbedaan kemampuan awal matematika siswa antara kelas eksperimen dengan kelas kontrol.

Dengan menggunakan taraf signifikansi $\alpha=0,05$, didapatkan nilai $t_{\text {hitung }}=$ 3,578 dan $t_{\text {tabel }}=1,684$ (uji dua arah) sehingga $-t_{\text {tabel }} \leq t_{\text {hitung }} \leq t_{\text {tabel }}=$ $-1,684 \leq 3,578 \leq 1,684$. Hal ini tidak sesuai dengan kriteria pengujian, maka hipotesis melalui uji-t $H_{0}$ ditolak sehingga $\mathrm{H}_{1}$ diterima yaitu terdapat perbedaan kemampuan awal siswa antara kelas eksperimen dengan kelas kontrol.

Tabel 3. Hasil Uji-t Pretest

\begin{tabular}{ccccc}
\hline $\boldsymbol{t}_{\text {hitung }}$ & $\boldsymbol{t}_{\text {tabel }}$ & Dk & Signifikan & Keterangan \\
\hline 3,578 & 1,684 & 58 & $5 \%$ & Terima $\mathrm{H}_{1}$ \\
\hline
\end{tabular}

\section{Uji Hipotesis Data Posstest}

Uji hipotesis pada data posstest digunakan untuk mengetahui kemampuan pemecahan masalah matematika siswa yang mendapatkan model pembelajaran Think Pair Share lebih baik dengan siswa yang mendapatkan pembelajaran ceramah. Dengan hipotesis:

$\mathrm{H}_{0} \quad$ : Kemampuan pemecahan masalah matematika siswa yang mendapatkan model pembelajaran Think Pair Share tidak lebih baik daripada siswa yang mendapatkan pembelajaran ceramah.

$\mathrm{H}_{1}$ : Kemampuan pemecahan masalah matematika siswa yang mendapatkan model pembelajaran Think Pair Share lebih baik daripada siswa yang mendapatkan pembelajaran ceramah.

Karena data yang didapat berdistribusi normal dan homogen maka uji yang digunakan adalah uji-t, menggunakan taraf signifikansi $\alpha=0,05$ dengan $d k=n 1+$ 
$n 2-2$, hasil perhitungan didapatkan nilai nilai $t_{\text {hitung }}=6,0711$ dan $t_{\text {tabel }}=$ 1,6723 (uji satu arah) sehingga $t_{\text {hitung }}>t_{\text {tabel }}$ yaitu 6,0711 $>1,6723$. Hal ini sesuai dengan kriteria pengujian, maka $H_{0}$ ditolak, sehingga kemampuan pemecahan masalah matematika siswa yang mendapatkan model pembelajaran Think Pair Share lebih baik daripada siswa yang mendapatkan pembelajaran ceramah.

Tabel 4.

Hasil Uji-t Posstest

\begin{tabular}{ccccc}
\hline $\boldsymbol{t}_{\text {hitung }}$ & $\boldsymbol{t}_{\text {tabel }}$ & Dk & Signifikan & Keterangan \\
\hline 6,0711 & 1,6723 & 58 & $5 \%$ & Tolak $\mathrm{H}_{0}$ \\
\hline
\end{tabular}

\section{Uji Hipotesis Data Gain}

Uji hipotesis digunakan untuk mengetahui apakah terdapat pengaruh penerapan model pembelajaran Think Pair Share terhadap peningkatan kemampuan pemecahan masalah matematika siswa kelas VIII SMPN SATAP 5 Banjarsari.

Karena salah satu data tidak homogen, maka menggunakan Uji Kesamaan Dua Rata-Rata (Uji t satu pihak kanan), menggunakan $\alpha=0,05$ didapatkan nilai $t_{\text {hitung }}=$ 6,7892 dan $t_{\text {tabel }}=1,6723$ sehingga $t_{\text {hitung }}>t_{\text {tabel }}$ yaitu 6,7892 $>1,6723$. Hal ini sesuai dengan kriteria pengujian, maka $H_{0}$ ditolak yang berarti bahwa terdapat pengaruh model pembelajaran Think Pair Share (TPS) terhadap peningkatan kemampuan pemecahan masalah matematika siswa kelas VIII SMPN SATAP 5 Banjarsari tahun pelajaran 2016/2017.

Tabel 5.

Hasil Uji-t Posstest

\begin{tabular}{ccccc}
\hline $\boldsymbol{t}_{\text {hitung }}$ & $\boldsymbol{t}_{\text {tabel }}$ & Dk & Signifikan & Keterangan \\
\hline 6,7892 & 1,6723 & 58 & $5 \%$ & Tolak $\mathrm{H}_{0}$ \\
\hline
\end{tabular}

Dari hasil pengolahan data yang dilakukan dapat diketahui bahwa model pembelajaran Think Pair Share dapat meningkatkan kemampuan pemecahan masalah matematika siswa, peningkatan terjadi karena proses pembelajaran siswa dihadapkan langsung dalam suasana kelas yang tidak monoton dengan diberikannya Think Pair Share. Siswa dihadapkan langsung dengan siswa yang lainnya sesuai dengan masing- 
masing kelompok, sehingga dapat berdiskusi dengan anggota kelompoknya, dan dapat mendorong siswa untuk berpartisipasi dengan aktif.

Meskipun penelitian telah dilakukan semaksimal mungkin, tetapi masih terdapat keterbatasan-keterbatasan dalam penelitan, diantaranya:

1. Waktu penelitian yang terbatas sehingga pokok bahasan yang bisa diteliti hanya pokok bahasan mengenai Faktorisasi Suku Aljabar.

2. Keterbatasan biaya juga mengakibatkan kurang maksimalnya hasil penelitian ini.

3. Pengambilan sampel yang belum mampu merepresentasikan keseluruhan siswa.

\section{KESIMPULAN}

Berdasarkan hasil pengolahan data dari penelitian yang telah dilakukan di SMPN SATAP 5 Banjarsari pada kelas VIII, data kemampuan pemecahan masalah matematika kelas eksperimen lebih tinggi dari pada kelas kontrol. Hal ini menunjukan bahwa dari segi keseluruhan kemampuan pemecahan masalah matematika siswa kelas eksperimen lebih baik dibandingkan dengan siswa kelas kontrol. Selain itu dari perhitungan uji gain menunjukan bahwa penggunakan model Think Pair Share terhadap peningkatan kemampuan pemecahan masalah matematika siswa. Dengan demikian model pembelajaran Think Pair Share dapat dijadikan sebagai alternatif pembelajaran matematika agar hasil yang diperoleh bisa lebih baik.

\section{E. REFERENSI}

Arikunto, S. (2012). Dasar-dasar Evaluasi Pendidikan, Ed. 2. Jakarta: Bumi Aksara Bubin, (2012). Meningkatkan Kemampuan Pemecahan Masalah Matematika Peserta Didik melalui Penggunaan Model Pembelajaran Kooperatif Tipe Think-PairShare, [online], Vol 1. Tersedia: http://journal.unsil.ac.id/jurnalunsil-197-html.

Fogarty dan Robin. (1996). Think/Pair/Share. [online]. Tersedia: www.Broward k12.fl.us/Ci/Whatsnew/strategies and such/ strategies/thinkpairshare. html [2 November 2009]

Maryanti, E. (2012). Peningkatan Literasi Matematis Siswa melalui Pendekan Metacognitive Guidance. Tesis pada Jurusan Pendidikan Matematika UPI Bandung: tidak diterbitkan.

Ruseffendi, E.T. (2005). Dasar-dasar Penelitian Pendidikan dan Bidang NonEksakta lainnya. Bandung : Tarsito.

Sugiyono, (2013). Metode Penelitian Pendidikan (PendekatanKuantitatif, Kualitatif, dan $R \& D)$. Bandung: $C V$. Alfabeta. 